\title{
DECISÃO DE SAZONALIZAÇÃO DE CONTRATOS DE FORNECIMENTO DE ENERGIA ELÉTRICA NO BRASIL ATRAVÉS DA OTIMIZAÇÃO DA MEDIDA ÔMEGA $(\Omega)$
}

\author{
Mario Domingues de Paula Simões \\ msimoes@alum.mit.edu \\ Pontifícia Universidade Católica do Rio de Janeiro - RJ / Brasil \\ Leonardo Lima Gomes \\ leonardolima@iag.puc-rio.br \\ Pontifícia Universidade Católica do Rio de Janeiro - RJ / Brasil
}

Recebido em 05/01/2009

Aprovado em 10/03/2009

Disponibilizado em 01/04/2011

Avaliado pelo sistema double blind review

Revista Eletrônica de Administração

Editor: Luís Felipe Nascimento

ISSN 1413-2311 (versão on-line)

Editada pela Escola de Administração da Universidade Federal do Rio Grande do Sul.

Periodicidade: Quadrimestral

Sistema requerido: Adobe Acrobat Reader.

\section{INTRODUÇÃO}

O setor elétrico brasileiro (SEB) passou por grandes mudanças nos últimos anos, destacando-se a reformulação do setor que foi iniciada a partir do segundo semestre de 1997, quando foram efetuadas as primeiras privatizações no setor. Até aquele ponto a situação era, basicamente, traduzida em um monopólio estatal administrado por empresas federais e estaduais. A partir daquele momento as privatizações foram iniciadas, ao mesmo tempo levando a uma grande reestruturação do setor.

As mudanças então iniciadas foram baseadas no chamado Projeto de Reestruturação do Setor (Projeto RE-SEB), coordenado pelo Ministério de Minas e Energia, apresentando como principais características:

- A desverticalização da produção, transmissão, distribuição e comercialização de energia elétrica;

- Os segmentos de produção e comercialização passaram a desfrutar de liberdade para competir, com preços contratados definidos pelo mercado;

REAd - Edição 68, Volume 17, No 1, jan/abr 2011 - p. 181-203 
- Geradores e comercializadores foram permitidos ter livre acesso às redes de transmissão e distribuição;

- Foi criado o Mercado Atacadista de Energia (MAE), atualmente rebatizado de Câmara de Comercialização de Energia Elétrica (CCEE), como sendo um ambiente de contabilização e liquidação da energia elétrica transacionada.

Em seguida, o formato de negociação de energia foi aprimorado. Os ambientes de negociação de energia elétrica foram estabelecidos no decreto $\mathrm{n}^{\mathrm{o}} 5.163$ de 30 de Julho de 2004, sendo regulamentados na forma do Ambiente de Contratação Livre (ACL) e Ambiente de Contratação Regulada (ACR).

O ACL é definido como o segmento do mercado no qual se realizam as operações de compra e venda de energia elétrica, objeto de contratos bilaterais livremente negociados. Já o ACR é o ambiente que envolve as contratações de energia com as distribuidoras por meio de processos regulados.

Empresas de geração podem vender energia tanto no ACR como no ACL a depender da estratégia adotada. No caso específico das hidrelétricas, essas possuem uma capacidade máxima de contratação de energia denominada energia assegurada.

A energia assegurada pode ser definida como a energia que uma hidrelétrica consegue disponibilizar ao sistema em uma situação hidrológica crítica, dado um nível de confiabilidade de $95 \%$. Por exemplo, uma hidrelétrica pode ter $450 \mathrm{MWmed}$ de capacidade instalada, mas apenas 200 MWmed de energia assegurada dada uma situação hidrológica desfavorável. Assim, esta hidrelétrica só poderá realizar contratos de venda totalizando até 200 MWmed.

Devido ao consumo sazonal de energia no Brasil, foi estabelecida uma flexibilidade para as hidrelétricas conhecida como sazonalização da energia assegurada sendo de particular interesse e objeto deste trabalho.

A sazonalização permite que, a cada ano, o agente de geração hidrelétrica declare para o ano seguinte o quanto será a energia mensal, respeitando-se os limites inferior de zero e superior da capacidade instalada, e o total anual da energia assegurada.

Assim, considerando o exemplo anterior, a hidrelétrica que detém 200 MWmed de energia assegurada pode escolher uma sazonalidade a partir da qual possui $400 \mathrm{MWmed}$ no mês de janeiro e 0 MWmed no mês de Dezembro, mantendo-se em 200 MWmed a energia assegurada nos outros meses. A média anual permaneceu em 200 MWmed e o limite superior da capacidade instalada não foi violado (450 MWmed). 
Dessa forma, é possível haver fornecimentos de energia, durante o período contratado, acima ou abaixo da média especificada, desde que o total fornecido no período obedeça ao contrato firmado.

Quando isso acontece, com a energia assegurada mensal sendo maior ou menor do que a energia contratada, as diferenças contabilizadas a maior ou a menor são liquidadas de acordo com os preços de curto prazo (Preço de Liquidação das Diferenças - PLD), que podem ser maiores ou menores do que o preço fixo contratual.

A análise da decisão da sazonalização é uma questão prática com a qual os agentes de geração hidrelétrica se deparam anualmente, sendo uma das principais decisões comerciais de um gerador.

Ressalta-se que as empresas de geração que realizam a sazonalização como uma operação descasada têm uma preocupação muito grande em controlar o risco e conseqüentemente o tamanho do descasamento. É comum que estas empresas utilizem o Value at Risk (VaR) para controlar a exposição ao risco de mercado. Na seção 3 será apresentada a definição de VaR.

Assim, a questão de pesquisa que se pretende abordar no presente trabalho diz respeito à seguinte situação: “Qual é a melhor forma de sazonalizar a Energia Assegurada maximizando o resultado da hidrelétrica, considerando-se restrições de valor em risco $(\operatorname{VaR})^{\prime \prime} ?$

No sentido de responder a esta questão, foi escolhido como critério de seleção da sazonalização a maximização da medida ômega $(\Omega)$ dado um nível de VaR. A medida $\Omega$ foi escolhida porque consegue incorporar todos os momentos da distribuição, fornecendo uma completa descrição das características do risco-retorno, de tal modo que resulta em uma medida intuitivamente atrativa e facilmente computável.

No caso específico de trabalhos sobre comercialização de energia elétrica no Brasil, observam-se distribuições de preços extremamente afastadas da normalidade, o que torna o uso da medida $\Omega$ particularmente valioso.

Além de procurar responder a uma pergunta associada a um problema real, este artigo contribui com a utilização de uma técnica recente de otimização de carteira que é a maximização da medida $\Omega$ com restrição de VaR. Adicionalmente, apresenta variáveis e especificidades do SEB pouco exploradas em trabalhos científicos brasileiros.

Este trabalho está organizado da seguinte forma: a seguir será feita uma introdução ao mercado de energia elétrica no Brasil buscando apontar e explicar algumas características deste mercado. Em continuidade, será feita uma revisão da literatura com uma explicação REAd - Edição 68, Volume 17, No 1, jan/abr 2011 - p. 181-203 
sobre a função ômega e suas particularidades. Após esta explicação, serão apresentadas a modelagem do problema, as soluções obtidas e, finalmente, serão enunciadas as conclusões e recomendações.

\section{O MERCADO DE ENERGIA ELÉTRICA NO BRASIL}

\subsection{Formatação dos Contratos}

No Brasil, a unidade básica negociada em contratos de energia elétrica é o megawatthora $(\mathrm{MWh})$, com os preços negociados em reais por megawatt-hora ( $\mathrm{R} \$ \mathrm{MWh})$. Um contrato especifica as quantidades de energia elétrica a serem entregues durante determinados intervalos de tempo.

Seja um contrato com prazo de dois meses, para entrega em março e abril de determinado ano, que determina que o fornecedor entregue 74.400 MWh em março e 72.000 MWh em abril. Se o preço contratado for de $50 \mathrm{R} \$ / \mathrm{MWh}$, o faturamento do fornecedor deverá ser de R\$ 50 x 74.400 em março e de R $\$ 50$ x 72.000 em abril.

Como os meses de março e abril têm, respectivamente, 744 e 720 horas, o valor médio de energia entregue será de 100 megawatts (MW). É bastante comum que a quantidade negociada seja expressa em MW, mais especificamente em MW médios (MWmed), indicando ser esta a média no período. A quantidade negociada, de $100 \mathrm{MWmed}$ para março e abril, equivale a 100 (MW) x 744 (horas) MWh em março e 100 (MW) x720 (horas) MWh em abril.

O mercado brasileiro de energia elétrica está dividido em quatro sub-mercados, embora o sistema seja integrado em âmbito nacional. Dependendo da situação do armazenamento de água, da oferta e da demanda, cada sub-mercado pode apresentar preços bastante diferentes. Daí a importância da especificação do local da entrega em cada contrato.

No exemplo aqui apresentado, o contrato seria expresso com as seguintes características:

- Ponto de Entrega: Sub-mercado Sudeste/Centro-oeste;

- Duração: Março e Abril do ano tal;

- Quantidade: 100 MWmed;

- Preço: $50 \mathrm{R} \$ / \mathrm{MWh}$.

\subsection{A Sazonalização}

Segundo a CCEE, "Sazonalização é o processo de alocar mensalmente um montante anual de energia, seja de um contrato ou a energia assegurada de uma usina”. Ou seja, trata-

REAd - Edição 68, Volume 17, No 1, jan/abr 2011 - p. 181-203 
se de uma das principais flexibilidades automaticamente inseridas na capacidade de fornecimento de uma hidrelétrica.

A sazonalização da Energia Assegurada possui como limites a máxima capacidade instalada e zero. Assim, uma Pequena Central Hidrelétrica $(\mathrm{PCH})$ de capacidade de geração de $20 \mathrm{MW}$, poderia ter uma quantidade de energia assegurada no âmbito da CCCE aferida em 10 MWmed, e poderia sazonalizar seu contrato de fornecimento de energia entre 0 e 20 MWmed, conforme sua expectativa das condições esperadas no período.

Supondo-se que a PCH do exemplo anterior tivesse contratado uniformemente toda a sua energia assegurada de $10 \mathrm{MWmed}$, no caso em que a energia sazonalizada mensal fosse abaixo dos 10 MWmed contratados, a diferença seria contabilizada como um débito contra este fornecedor, ao PLD do período. Ao contrário, seria um crédito nas mesmas condições.

Partindo-se da premissa de que a sazonalização levará a geradora a ter excedentes em alguns meses e déficits em outros, a simulação dos PLDs se torna uma informação bastante relevante na análise de decisão. A seguir, descreve-se como o PLD é formado a partir da operação ótima de um sistema hidrotérmico. 


\subsection{Formação e Simulação dos PLDs}

O PLD é utilizado para liquidar a compra e a venda de energia no mercado de curto prazo. A formação do preço da energia comercializada no mercado de curto prazo se faz pela utilização dos dados considerados pelo Operador Nacional do Sistema (ONS) para a otimização da operação.

O Brasil adotou um esquema de decisão de operação centralizado realizado por modelos acoplados de otimização, sendo um modelo de médio prazo acoplado a um de longo prazo, chamado Newave, cujo objetivo é minimizar o custo total de operação do sistema hidrotérmico ao longo de um horizonte de planejamento. Esses modelos utilizam o método de programação dinâmica dual estocástica descrita em Pereira e Pinto (1991). A fim de conceituar melhor a formação de preço no sistema hidrotérmico brasileiro, torna-se necessária uma abordagem sobre como é feita a operação sob uma ótica econômica. As seções a seguir apresentam essa abordagem.

\subsection{Operação de um Sistema Hidrotérmico}

A característica mais evidente de um sistema com geração hidroelétrica é poder utilizar a energia "grátis" que está armazenada nos reservatórios para atender à demanda evitando, desta maneira, gastos de combustível com as unidades térmicas. Entretanto, a disponibilidade de energia hídrica está limitada pela capacidade de armazenamento nos reservatórios. Isto introduz uma dependência entre a decisão operativa de hoje e os custos operativos no futuro.

Em outras palavras, se utilizarmos hoje as reservas de energia hídrica, com o objetivo de minimizar os custos térmicos, e ocorre uma seca severa no futuro, pode haver um racionamento de custo elevado para a sociedade. Se, por outro lado, preservamos as reservas de energia hídrica, através de um uso mais intenso de geração térmica, e as afluências futuras são elevadas, pode ocorrer um vertimento nos reservatórios do sistema, o que representa um desperdício de energia e, conseqüentemente, um aumento no custo operativo. Esta situação está ilustrada na Figura 1. 


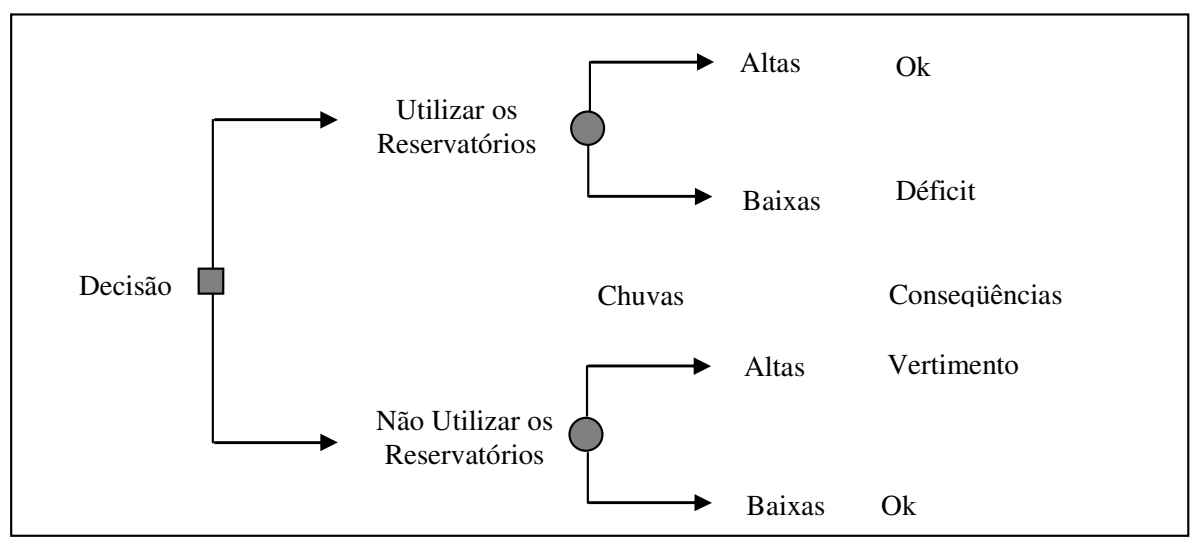

Figura 1 - Processo de Decisão para Sistemas Hidrotérmicos

O operador de um sistema hidrotérmico deve comparar o benefício imediato do uso da água e o benefício futuro de seu armazenamento, conforme ilustrado na Figura 2.

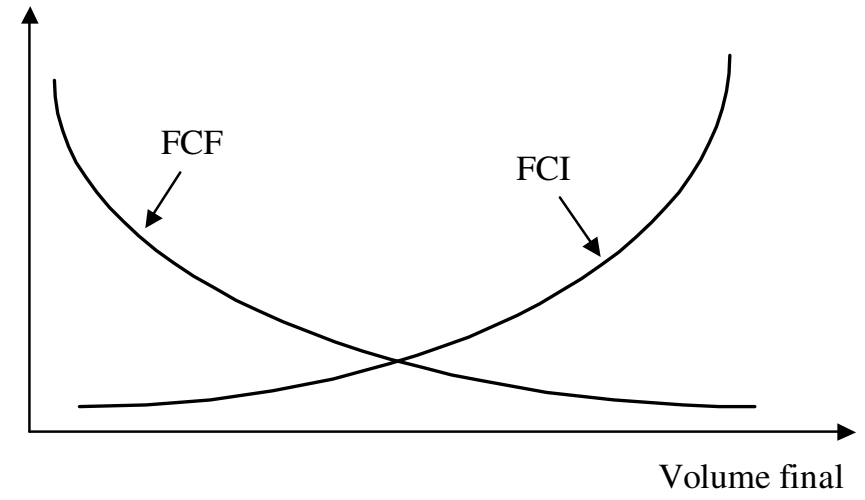

Figura 2 - Custo imediato e Futuro

A função de custo imediato - FCI - representa os custos de geração térmica no estágio $t$, ou seja, no estágio imediato, presente. Observa-se que o custo imediato aumenta à medida que diminui a energia hídrica disponível, isto é, quanto menor for a decisão de geração hídrica, maior será a de geração térmica.

Por sua vez, a função de custo futuro - FCF - está associada ao custo esperado de geração térmica e racionamento do final do estágio $t$ (início de $t+1$ ) até o final do período de estudo. Esta função diminui à medida que aumenta o volume armazenado final, pois haverá mais energia hídrica disponível no futuro.

O uso ótimo da água armazenada corresponde ao ponto que minimiza a soma dos custos imediato e futuro. Como é mostrado na Figura 3, o ponto de mínimo custo global também corresponde ao ponto onde as derivadas da FCI e da FCF com relação ao armazenamento de água se igualam. A derivada da FCI e da FCF no ponto ótimo também é conhecida como valor da água, pois representa a taxa custo $\mathrm{R} \$$ (ou valor) por volume de água deixado no reservatório para formar o volume final. 


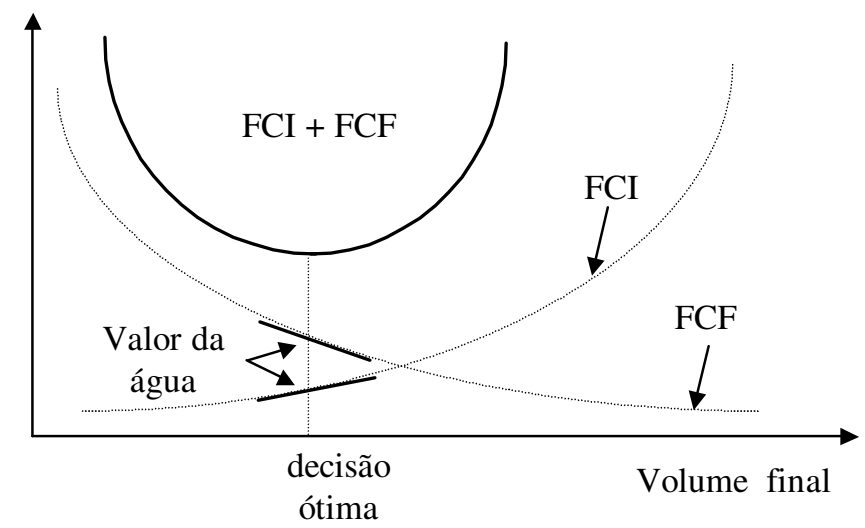

Figura 3 - Uso Ótimo da Água

\subsection{Cálculo do PLD - Preço de Liquidação das Diferenças}

Será apresentado, mais detalhadamente, como é realizada a decisão de operação sob a ótica econômica e calculado o PLD. Na formulação a seguir, estamos supondo que a função de custo futuro para cada estágio foi calculada. O problema de decisão da operação hidrotérmica para o estágio $t$ é formulado como:

$$
Z_{t}=\operatorname{Min}\left[c_{j} \times g_{t j}+F C F\left(v_{t+1}\right)\right]
$$

Sujeito às seguintes restrições operativas:

- Balanço hídrico;

- Limites de armazenamento de água e turbinamento;

- Limites na geração térmica;

- Atendimento à demanda.

A função objetivo é minimizar a soma de duas classes de custos:

- Custo operativo imediato - dado pelos custos térmicos $\left\{\mathrm{c}_{\mathrm{j}} \times \mathrm{g}_{\mathrm{tj}}\right\}$ no estágio t. Onde $\mathrm{c}_{\mathrm{j}}$ é o custo variável da térmica $\mathrm{j}$ e $\mathrm{g}_{\mathrm{tj}}$ é a geração da térmica $\mathrm{j}$ no estágio $\mathrm{t}$. $\mathrm{O}$ racionamento é representado por uma térmica fictícia de capacidade infinita e custo operativo igual ao custo de interrupção.

- Valor esperado do custo operativo futuro - dado pela função de custo futuro $\mathrm{FCF}\left(\mathrm{v}_{\mathrm{t}+1}\right)$. Também como discutido anteriormente, esta função depende dos volumes armazenados ao final do estágio, representados pelo vetor $\mathrm{v}_{\mathrm{t}+1}$.

O problema de otimização pode ser resolvido por um algoritmo de programação linear. Além da decisão operativa ótima, o esquema de programação linear calcula os multiplicadores simplex, ou preços sombra, associados a cada restrição. Em particular, o PLD REAd - Edição 68, Volume 17, No 1, jan/abr 2011 - p. 181-203 
do sistema é praticamente o multiplicador simplex associado à restrição de atendimento à demanda, significando o custo de produção de $1 \mathrm{MWh}$ adicional no ponto ótimo de minimização de custos (em R \$MWh).

\subsection{Simulação dos PLDs - Preços de Liquidação das Diferenças}

O modelo Newave possui dois módulos. No primeiro é calculada a política ótima de operação ao longo do horizonte de planejamento, representando um "mapa de decisão" em função do que vier a ocorrer ou ser simulado em termos de afluências (chuvas) aos reservatórios. No segundo módulo são feitas simulações do custo marginal de operação (que é praticamente o PLD publicado), ou seja, o quanto custa produzir um MWh adicional de energia no ponto ótimo.

Após a utilização do modelo Newave para calcular a política ótima de operação hidrotérmica ao longo de um período de planejamento, pode ser feita uma simulação com a qual se obtêm séries de custos marginais de operação, e, conseqüentemente, obtêm-se séries de PLDs. A simulação é realizada mediante a geração de séries sintéticas de afluências aos reservatórios, utilizando um modelo periódico auto-regressivo $(\mathrm{PAR}(\mathrm{p}))$ de séries temporais. Maceira e Bezerra (1997) apresentam esta metodologia.

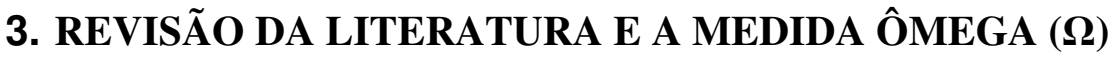

\subsection{Alguns Métodos de Escolha de Carteiras}

O trabalho de Markowitz (1952) foi o precursor na análise de decisão em formação de carteiras. O autor utilizou a variância do retorno da carteira como medida de risco. Em seu trabalho, deseja-se obter uma carteira de risco mínimo, ou seja, de variância mínima sujeito a restrições de uso do capital e de limite mínimo de retorno na carteira.

O risco sobre o retorno pode ser tratado como uma variável aleatória, sendo que apenas o segundo momento da distribuição de probabilidades do retorno é o indicador que define a maior ou menor exposição ao risco ao qual o ativo está exposto.

Adicionalmente ao trabalho desenvolvido por Markowitz, surgiram medidas e índices de desempenho utilizados para escolher carteiras. Os resultados formalizados pelos tradicionais trabalhos de Treynor (1965), Sharpe (1966) e Jensen (1968) contribuíram com alguns índices amplamente conhecidos e aceitos no mercado. A partir destes, a literatura cita inúmeros trabalhos que abordaram a análise de risco, enriquecendo de sobremaneira as alternativas para a mensuração de resultados. 
O índice de Sharpe (IS), por exemplo, avalia o desempenho de uma carteira levando-se em conta a divisão entre o retorno esperado e o desvio padrão do retorno da carteira.

$\mathrm{Na}$ evolução dos critérios de escolha de carteiras e controle de risco, surgiu o Value at Risk (VaR), forma de quantificação desenvolvida pelo banco JP Morgan (1996). Esta é uma forma sistemática resultante do esforço de determinar, a cada período, qual o valor de perda dado certo nível de significância estatística.

Assim, um $\mathrm{VaR}_{95 \%}$ traduz, em um número, que há 5\% de probabilidade de que um valor maior do que o indicado seja perdido. Isto quer dizer que, dada a distribuição de valores que se acredita válida, por exemplo, a distribuição de retornos de determinada carteira, o VaR corresponderá ao valor associado a um percentil extremo definido daquela distribuição (normalmente $1 \%$ ou $5 \%$ ).

\subsection{A Medida Ômega}

Muitas dificuldades são encontradas no momento de definir uma adequada medida de desempenho de um ativo ou de uma carteira. A maioria dos indicadores considera duas importantes simplificações: a média e a variância descrevem completamente a distribuição de retornos.

Estas simplificações são válidas se é assumida uma distribuição normal dos retornos ou valores, mas é geralmente aceito o fato empírico de que os retornos dos investimentos não possuem uma distribuição normal. Assim, além da média e variância, momentos de ordem superior seriam necessários para descrever melhor a distribuição.

Apresentada por Keating e Shadwick (2002), a medida Ômega $(\Omega)$ consegue incorporar todos os momentos da distribuição. Ela fornece uma completa descrição das características do risco-retorno, de tal modo que resulta em uma medida intuitivamente atrativa e facilmente calculada. Ao invés de estimar alguns momentos individuais, a medida $\Omega$ considera o impacto total da distribuição, o qual é certamente de interesse dos tomadores de decisão.

A medida $\Omega$, por definição, leva em conta um nível de retorno ou valor chamado de "limite" (L), definido exogenamente, o qual é a fronteira entre o que se considera como ganho e como perda. Mesmo em distribuições normais, dependendo do valor do L, a medida $\Omega$ fornece informações adicionais que só a média e variância não conseguiriam. Isto levaria a obter diferentes resultados em otimização de carteiras, se comparado com a otimização clássica de Markowitz.

Cabe destacar que a definição de um limite (L), também interpretado como uma meta, possui alta aderência com a realidade das empresas e do mercado financeiro. Empresas e REAd - Edição 68, Volume 17, No 1, jan/abr 2011 - p. 181-203 
investidores estão habituados a definirem metas, abaixo das quais se considera perda e acima das quais se considera ganho.

A utilização da medida $\Omega$ é recente, tendo grande potencial de desenvolvimento e novas aplicações. Alguns trabalhos que empregaram este índice de performance podem ser citados. Kazemi, Schneeweis e Gupta (2003) discutem o uso da medida, trazendo como contribuição a demonstração de que a função Omega $\Omega(\mathrm{L})$ pode ser escrita como uma divisão de dois valores esperados. Ick e Nowak (2006) fazem uma proposta para otimizar uma carteira de ações utilizando a medida $\Omega$. Castro (2008) utiliza a otimização da medida $\Omega$ na escolha de carteiras de projetos com opções reais. Ele aplicou a metodologia desenvolvida a projetos do setor petrolífero brasileiro.

\subsection{Definição e Cálculo da Medida Ômega}

Com a finalidade de exemplificar o cálculo da medida $\Omega$ será considerada uma distribuição de retornos de um ativo apresentada na Figura 4. A meta (ou limite) de retorno adotada foi de $\mathrm{L}=1,2$.

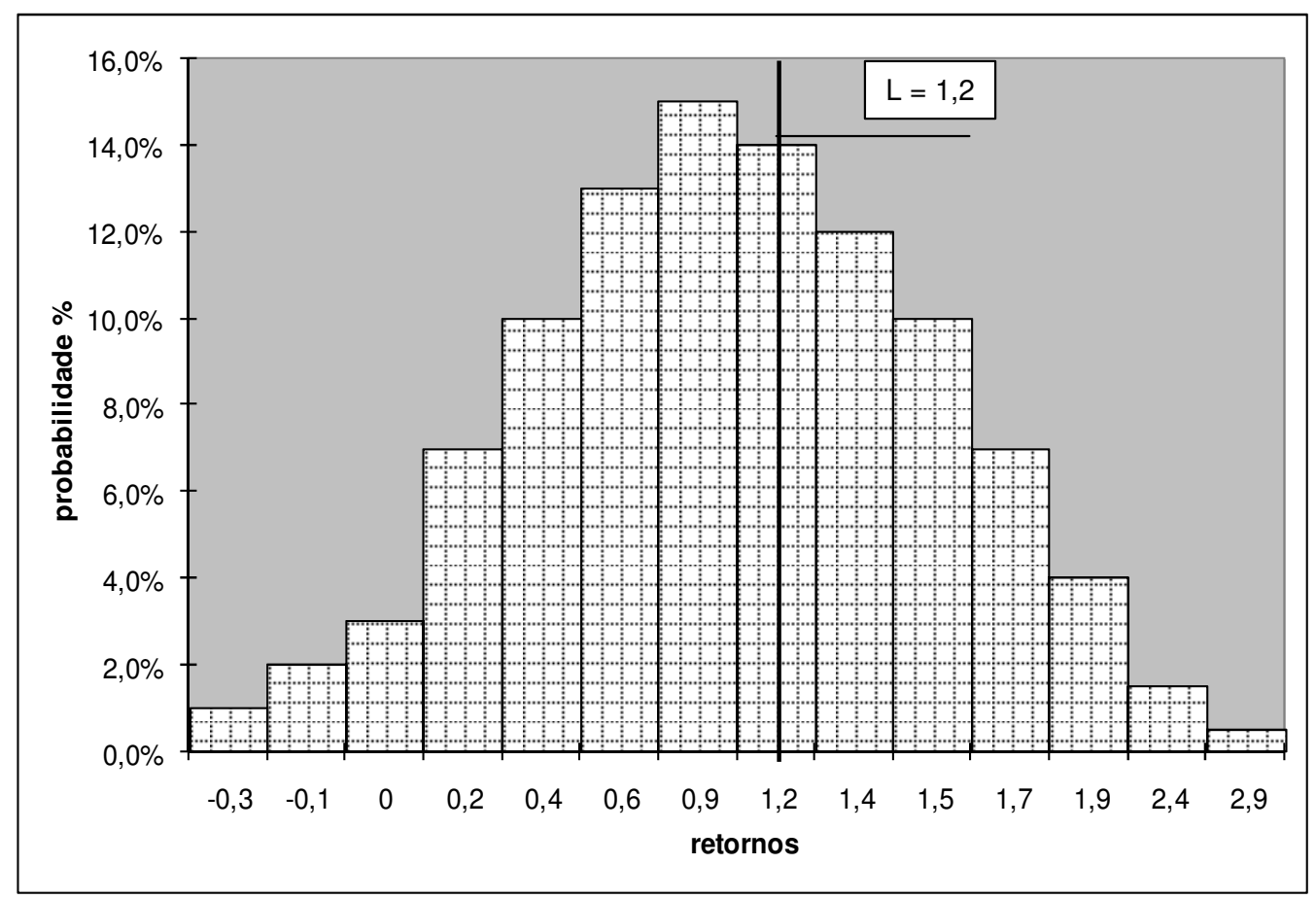

Figura 4 - Distribuição de Probabilidade dos Retornos, Exemplo

Esta distribuição servirá para ilustrar o conceito da medida $\Omega$ e a forma de calcular o valor da função $\Omega$ para um determinado limite $L$, dada uma distribuição de retornos esperada para um ativo, seja ele um ativo único ou uma carteira ou coleção deles (CASTRO, 2008).

Assim, uma vez dada a distribuição e especificado o limite L, pode-se comparar a probabilidade de ganhos e perdas, ponderados pelo seu valor. O ganho esperado de um REAd - Edição 68, Volume 17, No 1, jan/abr 2011 - p. 181-203 
retorno maior do que L é o valor esperado (condicional) dos retornos que excedem $\mathrm{L}$ ou $\mathrm{E}(\mathrm{r} \mid \mathrm{r} \geq \mathrm{L})$. A perda esperada é obtida como $\mathrm{E}(\mathrm{r} \mid \mathrm{r}<\mathrm{L})$.

Desta forma, o ganho esperado e a perda esperada, no caso da distribuição da Figura 4, podem ser calculados como:

$$
\begin{aligned}
& \gamma=\mathrm{E}(\mathrm{r} \mid \mathrm{r} \geq \mathrm{L})-\mathrm{L}=\mathrm{E}(\mathrm{r} \mid \mathrm{r} \geq 1,2)=(1,2+1,4+1,5+1,7+1,9+2,4+2,9) / 7-1,2=0,66 \\
& \varsigma=\mathrm{E}(\mathrm{r} \mid \mathrm{r}<\mathrm{L})-\mathrm{L}=\mathrm{E}(\mathrm{r} \mid \mathrm{r}<1,2)=(-0,3-0,1+0+0,2+0,4+0,6+0,9) / 7-1,2=-0,96
\end{aligned}
$$

Visualmente tem-se uma situação como a que é mostrada na Figura 4. É importante que os valores médios esperados dos ganhos e perdas não são informativos por si só, mas devem ser ponderados pelas suas probabilidades.

Assim, se $\mathrm{F}(\mathrm{r})$ for a função de distribuição cumulativa de probabilidades para os retornos, tem-se que: A probabilidade de que um retorno seja menor do que o limite $\mathrm{L}$ é $\mathrm{F}(\mathrm{L})$ e a probabilidade de que um retorno seja maior do que o limite L é 1-F(L).

A medida Ômega pode ser definida, então, como $\Omega=[\gamma \times(1-F(L))] /[\varsigma \times F(L)]$, o que daria uma indicação da qualidade do retorno dos ativos, em relação ao limite requerido L. Na Figura 5, apresenta-se a distribuição cumulativa de retornos para o ativo do exemplo. Pode-se observar o índice Ômega através de seus numerador e denominador, os retângulos superior direito e inferior esquerdo, respectivamente.

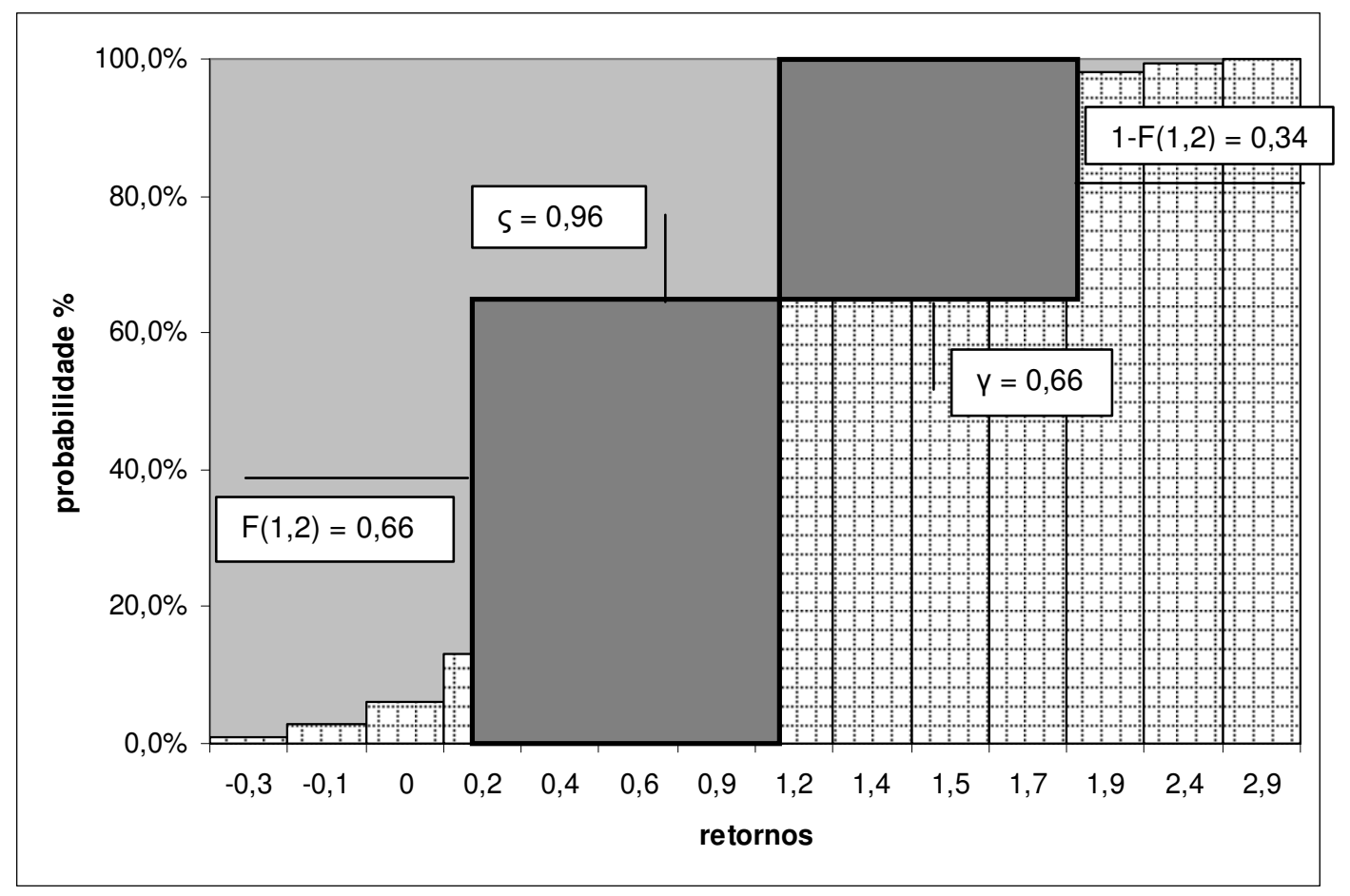

Figura 5 - Ilustração das Parcelas Ganho e Perda 
Conforme visualizado no gráfico da Figura 5 pode ser determinado o valor de $\Omega$ como sendo $\Omega=(0,66 \times 0,34) /(0,96 \times 0,66)=0,354$. Entretanto, este cálculo de $\Omega$ apenas considera um valor para os ganhos, o ganho médio, e um único para as perdas. Aprimorandose o cálculo, podem ser utilizados todos os valores disponíveis no intervalo, conforme ilustrado na Figura 6.

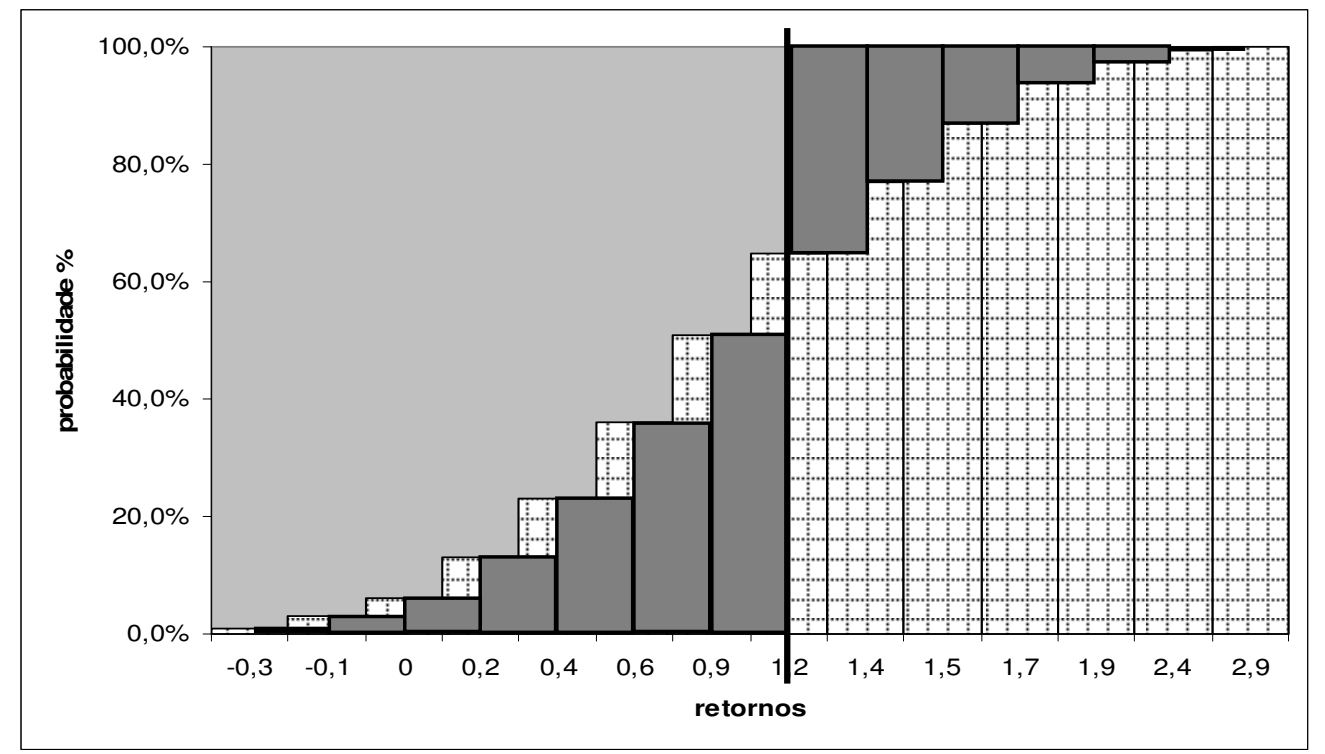

Figura 6 - Ilustração das Parcelas Ganho e Perda com Todos os Valores

Quando a distribuição de probabilidades deixa de ser discreta, isto é, quando ela realmente torna-se uma função de densidade definida em todo o conjunto dos números reais, e os intervalos de valores de retornos tornam-se menores até o limite em que tendem a zero, a forma serrilhada da curva de distribuição cumulativa aproxima-se de uma linha contínua e o cálculo da função Ômega, para uma certa distribuição de frequiência e dado um limite dos retornos requerido $\mathrm{L}$, torna-se o valor $\Omega(\mathrm{L})$ e é o resultado da divisão da área superior pela inferior do gráfico, conforme mostrado na Figura 7. 


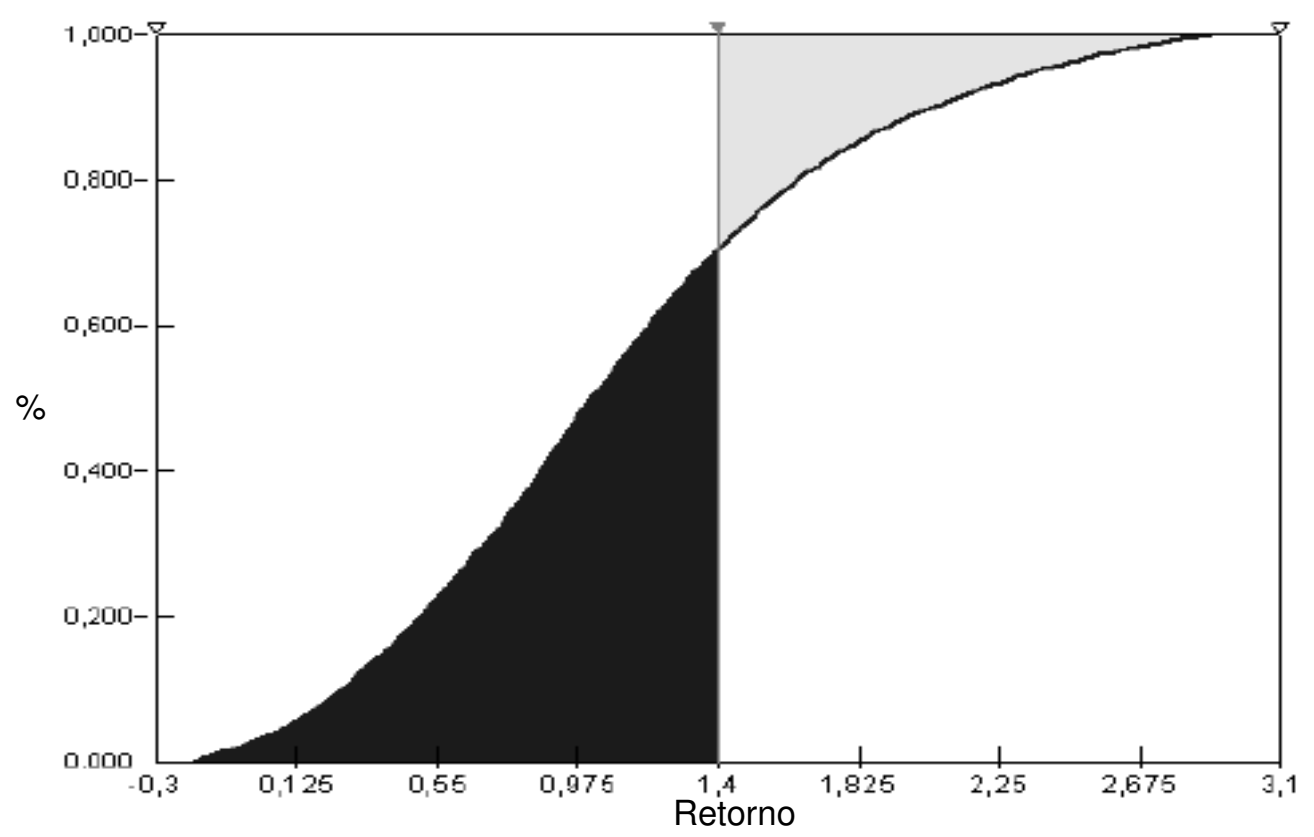

Figura 7 - Ilustração das Parcelas Ganho e Perda com Todos os Valores

A função Ômega, na forma de sua definição e calculada na sua forma contínua, pode ser definida de acordo com a equação:

$$
\Omega(L)=\frac{I_{2}}{I_{1}}=\frac{\int_{L}^{b}[1-F(x)] d x}{\int_{a}^{L} F(x) d x}
$$

onde: $\quad F(x)=$ função de distribuição cumulativa (FDC) dos retornos “ $x$ ”

$L$ = nível mínimo requerido dos retornos

$a=$ menor retorno

$b=$ maior retorno

A função $\Omega(\mathrm{L})$ assim definida engloba todas as características da distribuição de retornos, pois considera toda a função de distribuição destes, incorporando todos os efeitos dos momentos de ordem superior que porventura possam ser relevantes. Mais detalhes sobre a definição e as propriedades da medida $\Omega$ podem ser encontrados em Kazemi, Schneeweis e Gupta (2003). 


\section{METODOLOGIA}

\subsection{Modelagem dos Resultados Considerando Sazonalização}

A sazonalização da quantidade de energia assegurada versus a quantidade contratada uniforme, em contratos de fornecimento de energia elétrica, será decidida em função dos ganhos esperados da comercialização da energia de acordo com as condições contratuais vis $a$ vis os resultados obtidos com sua venda ou compra no mercado livre ao PLD do momento.

Assim, em primeiro lugar, é necessário que sejam definidos os limites possíveis desta sazonalização. Em seguida, deve-se obter um conjunto de PLDs simulados, preços de liquidação para esta energia, a cada momento.

Será considerado aqui o caso de uma PCH com energia assegurada de 10 MWmed e um respectivo contrato de venda no mesmo montante e uniforme ao longo dos meses. Esta PCH tem uma capacidade instalada de 20 MWmed. Assim, o limite mensal de sazonalização é de $100 \%$ para cima ou para baixo, isto é, com entrega de 0 a $20 \mathrm{MWmed}$, a cada mês.

O resultado de uma sazonalização da energia assegurada, para o caso desta PCH, será a diferença entre o valor da energia produzida e entregue nas condições de contrato, e o da energia comprada no mercado livre (no caso de entrega menor do que o valor contratado) ou da energia vendida naquele mercado (no caso de entrega maior do que o valor assegurado), para cada mês de liquidação.

Para cada uma destas situações, a única variável a ser considerada é o preço de liquidação das diferenças (PLD), uma vez que todos os demais fatores são constantes ou fixos, e iguais para quaisquer das alternativas.

Para cada mês considerado, a seguinte equação (3) traduz os resultados obtidos em relação ao contrato de venda de energia uniforme e a preço fixo:

$$
\sum_{i=1}^{12} R_{i}=\sum_{i=1}^{12}\left(E a_{i}-E c\right) \times\left(h_{i}\right) \times\left(P L D_{i}-P c\right) \times(1-I)
$$

onde:

$$
\begin{aligned}
& i=\text { mês } \\
& R=\text { resultado apurado } \\
& E a=\text { energia assegurada (MWmed) } \\
& E c=\text { energia contratada (MWmed) } \\
& h=\text { número de horas no mês } \\
& P L D=\text { PLD médio mensal (R } \$ / \mathrm{MWh}) \\
& P C=\text { preço contratado (R } \$ / \mathrm{MWh}) \\
& I=\text { total de impostos e taxas }
\end{aligned}
$$

REAd - Edição 68, Volume 17, No 1, jan/abr 2011 - p. 181-203 
É importante notar que o resultado da equação (3) é o valor em $\mathrm{R} \$$, referente à soma mensal dos superávits ou déficits de uma determinada sazonalização durante o período de um ano, em relação a entrega (venda) "flat" pura e simples.

Estes cálculos podem ser baseados em séries simuladas dos PLDs para o período em questão. Ora, a coleção de resultados calculados de acordo com a equação (3) produzirá uma distribuição de probabilidade de valores. Por exemplo, para a simulação de 2000 séries de PLDs serão obtidas 2000 séries de valores mensais, chegando-se a 2000 resultados anuais.

\subsection{Cálculo e Simulação dos PLDs}

A formação e simulação dos PLDs foi efetuada através do modelo Newave- versão 14, elaborado pelo Centro de Pesquisas de Energia Elétrica (CEPEL). O modelo otimiza a estratégia de geração de longo prazo de acordo com o conceito comentado anteriormente, simulando preços em base mensal. Cabe ressaltar que este é o modelo utilizado na formação dos preços de curto prazo (PLD) publicados na CCEE.

Foram utilizados os dados de entrada empregados no programa mensal de operação de agosto/2008, coordenado pelo Operador Nacional do Sistema (ONS). Foram considerados um piso de preço de R $\$ 15,47 / \mathrm{MWh}$ e um teto de R \$ 569,59/MWh, segundo o Despacho ANEEL $\mathrm{N}^{\mathrm{o}} 002$ de $04 / 01 / 2008$.

As 2000 séries de preços obtidas formaram a distribuição estatística de preços prováveis para o período em que se deseja analisar e calcular a sazonalização ótima, que forneça um resultado máximo possível de ser obtido.

\subsection{Dados Básicos}

Os dados do contrato de venda e das condições de sazonalização considerados no exemplo desenvolvido são apresentados a seguir:

- Contrato de 10 MWmed mensais de energia assegurada;

- Capacidade máxima de geração de 20 MW;

- Sazonalização de entrega mensal de 0 a 20 MWmed;

- Preço contratado de venda de R\$100/MWh;

- Impostos totais de 43,25\% (IR, CSSL, PIS e COFINS).

Estas características são bastante semelhantes à situação de uma $\mathrm{PCH}$, conforme modelo adotado no Brasil, tornando este estudo bastante relevante a operadores deste tipo de usina.

REAd - Edição 68, Volume 17, No 1, jan/abr 2011 - p. 181-203 
A Figura 8 que se segue mostra os percentis referentes às distribuições de probabilidade referentes aos PLDs simulados.

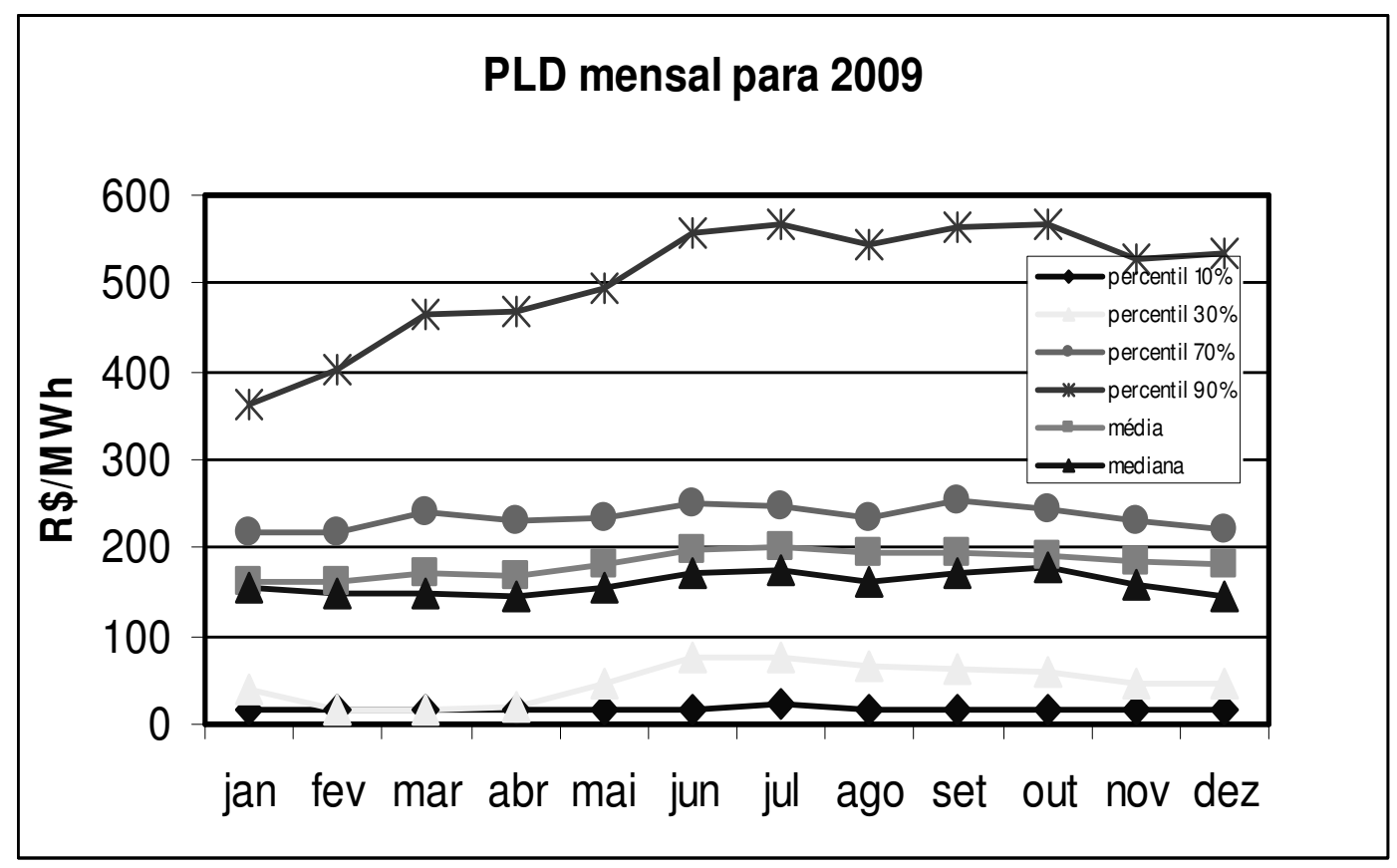

Figura 8 - Percentis Referentes à Simulação de PLDs

\subsection{Otimização e Convergência}

Os cálculos foram efetuados em um computador do tipo PC, usando-se uma planilha MS Excel e com a ajuda dos programas add-in Solver e Solver Premium, integrados à própria planilha.

A configuração das opções de execução do add-in Solver, por todo o trabalho apresentado foi a seguinte, conforme Figura 9.

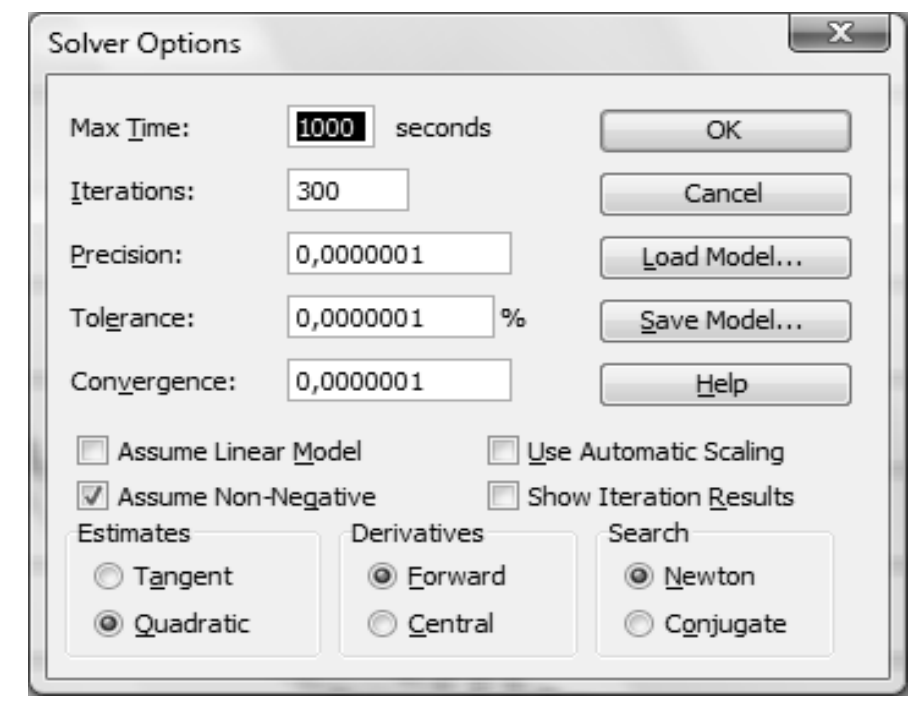

Figura 9 - Opções de execução do add-in Solver

REAd - Edição 68, Volume 17, No 1, jan/abr 2011 - p. 181-203 


\section{RESULTADOS}

Foram realizadas várias análises de sensibilidade, analisando-se como a medida $\Omega$ varia com a mudança da meta e do VaR. Adicionalmente, estudou-se o comportamento da decisão de sazonalização propriamente dita variando-se a meta e o VaR.

\subsection{Variação do $\Omega$ e do VaR 95\% em Função da Meta}

A fim de evidenciar o comportamento do $\Omega$ e do $\operatorname{VaR}_{95 \%}$ em função do limite $\mathrm{L}$ estabelecido, este foi variado desde zero até pouco mais de $\mathrm{R} \$ 2,3$ milhões, com o resultado sendo mostrado na Figura 10.

Como pode ser observado, o valor de ômega cai rapidamente desde cerca de 4 , tendendo a uma assíntota próxima de zero. Com uma sazonalização ótima podendo render algo em torno de $\mathrm{R} \$ 600$ mil / ano, há uma relação da ordem de 1:1, entre ganhos e perdas. A partir da Figura 10 também se pode observar que o $\mathrm{VaR}_{95 \%}$ sobe rapidamente, tendendo para um valor assintótico em torno de $\mathrm{R}$ \$2,6 milhões.

\subsection{Variação do $\Omega$ Fixando o VaR $\mathbf{V}_{95}$}

Os valores do limite $\mathrm{L}$ considerados foram de $\mathrm{R} \$ 0,5$ milhão a pouco menos de $\mathrm{R} \$ 1,3$ milhão. Foram obtidas seis curvas de $\Omega$ travando-se o $\mathrm{VaR}_{95 \%}$ de 0,5 a 3,0 milhões de $\mathrm{R} \$$ / ano.

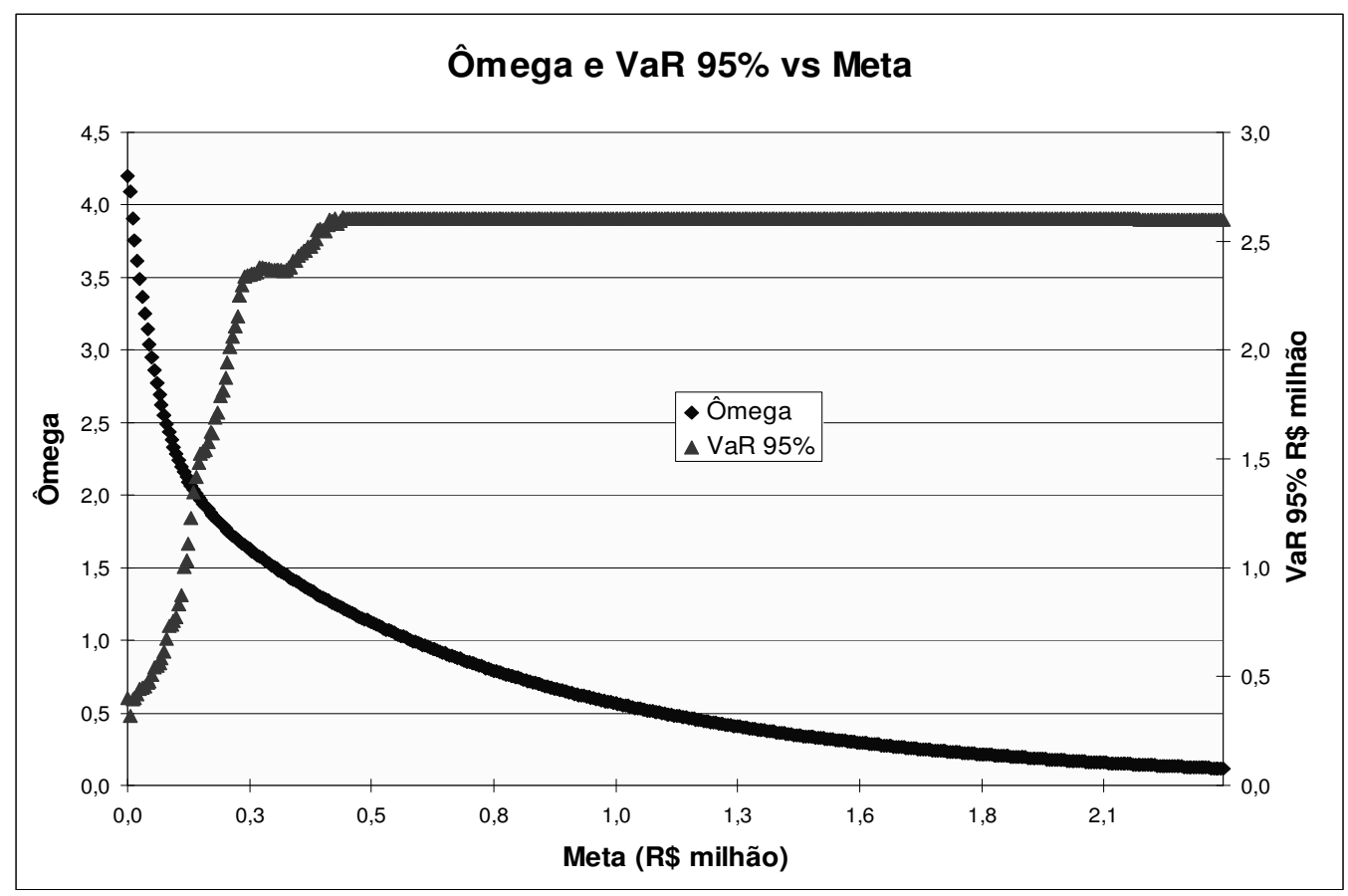

Figura 10 - $\Omega$ e VaR95\% Variando-se a Meta (limite L) 
As curvas apresentadas na Figura 11 mostram uma oscilação maior de valores ótimos para os níveis de $\mathrm{VaR}_{95 \%}$ mais restritivos, que correspondem a valores $\Omega$ mais baixos.

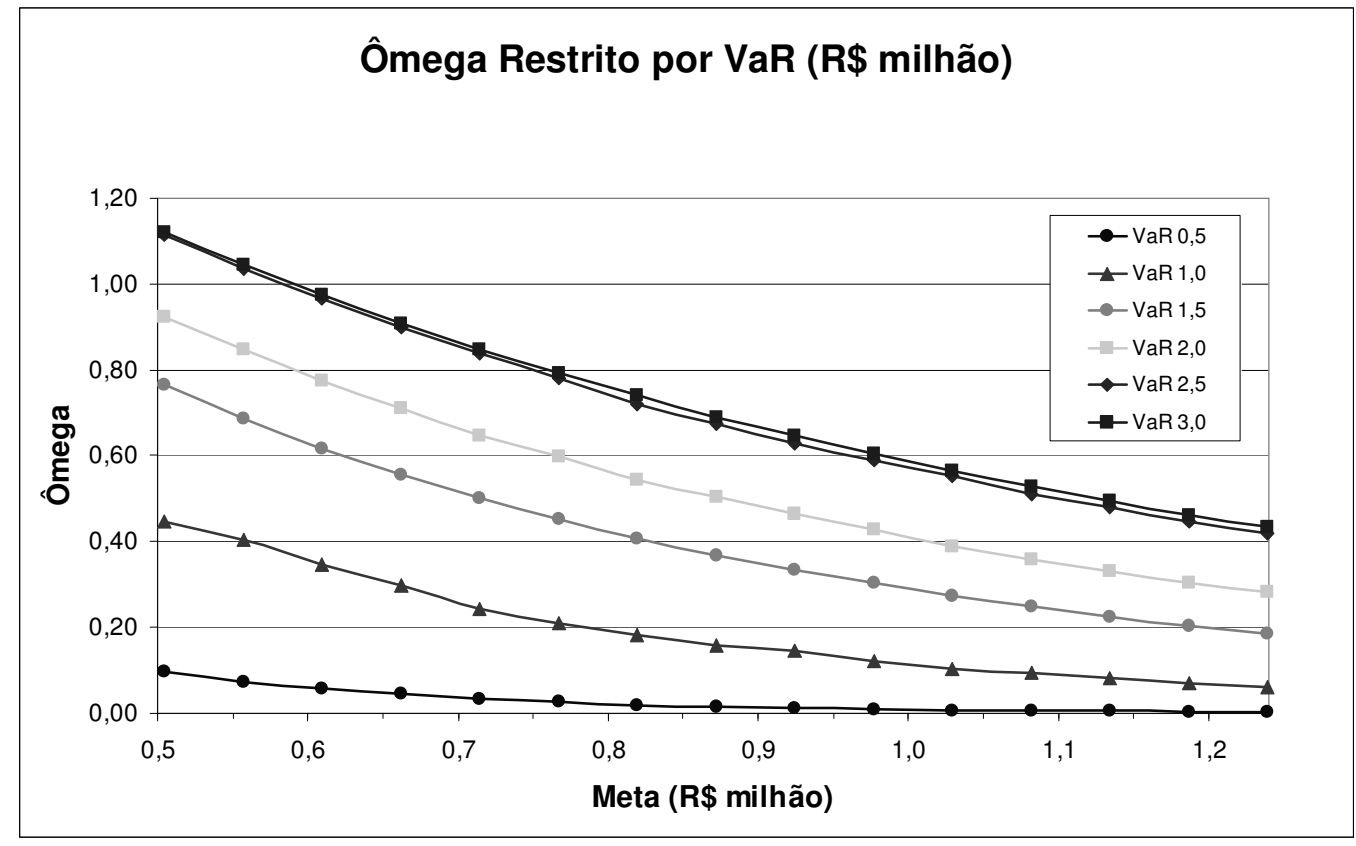

Figura 11 - $\Omega$ com restrição de $\operatorname{VaR}_{95} \%$

Também fica claro, e se pode facilmente observar, que as restrições mais intensas de $\mathrm{VaR}_{95 \%}$ implicam em valores de ômega extremamente pequenos. Isto denota que, se por um lado pretende-se minimizar riscos através da imposição de valores de VaR reduzidos, por outro lado, torna-se difícil alcançar metas um pouco mais audaciosas, uma vez que os níveis de $\Omega$ serão próximos a zero.

\subsection{Sensibilidade de $\Omega$ e VaR $\mathbf{R}_{95}$ ao Preço Contratado}

A Figura 12 mostra os resultados esperados para níveis de valor contratado com uma variação de $20 \%$ para mais ou para menos do valor de $100 \mathrm{R} \$ / \mathrm{MWh}$.

Valores mais baixos para o preço do contrato de venda, e por conseguinte maiores diferenças possíveis entre os PLDs atingidos (para cima) e o valor base, parecem favorecer ganhos com uma sazonalização ótima da entrega de energia. 
DECISÃO DE SAZONALIZAÇÃO DE CONTRATOS DE FORNECIMENTO DE 200

ENERGIA ELÉTRICA NO BRASIL ATRAVÉS DA OTIMIZAÇÃO DA MEDIDA

ÔMEGA $(\Omega)$

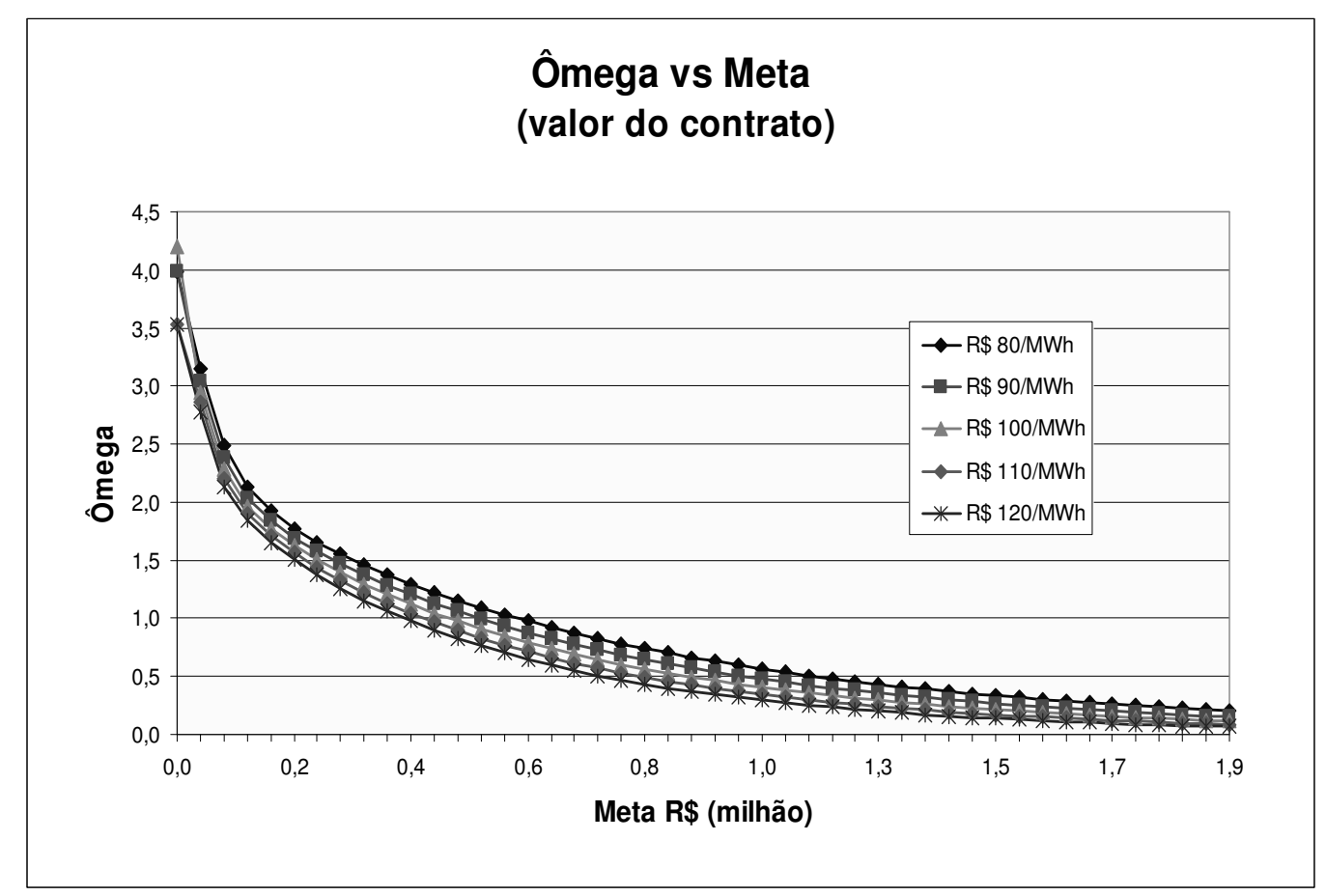

Figura 12 - $\Omega$ versus Preços Contratuais

\subsection{Perfil de Entrega Sazonalizada}

Tendo sido feitas as diversas avaliações mostradas anteriormente, resta saber qual o perfil ideal de entrega de energia em função dos parâmetros escolhidos, seja com restrição ou sem restrição de $\mathrm{VaR}_{95 \%}$.

Nas Figuras 13 e 14, a seguir, pode ser visto o perfil de entrega mensal para diversos tipos de sazonalização da entrega mensal de energia.

A Figura 13 apresenta a sazonalização ótima adotando-se metas de 0,6, 0,93 e 1,0 milhão de R $\$$ / ano. Não há restrição de $\mathrm{VaR}_{95 \%}$. Observa-se que a decisão de sazonalização é praticamente a mesma para as três situações. Ou seja, concentrando-se toda a energia assegurada entre junho e novembro.

REAd - Edição 68, Volume 17, No 1, jan/abr 2011 - p. 181-203 


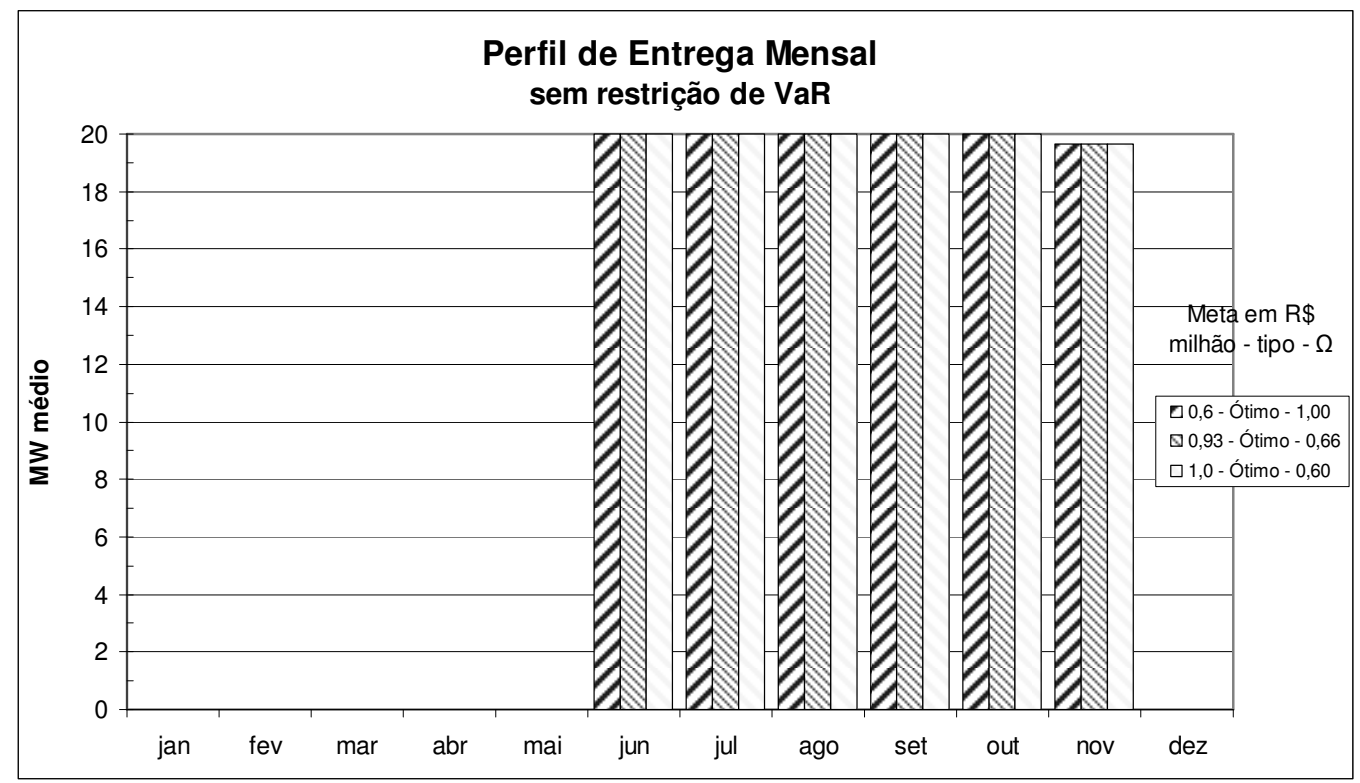

Figura 13 - Perfil Ótimo de Entrega Sazonalizada sem Restrições

A Figura 14 apresenta a sazonalização ótima adotando-se metas de 0,6 e 1,0 milhão de R \$ / ano. Existem três situações. Na primeira, não há restrição de $\mathrm{VaR}_{95 \%}$. Nas outras duas há restrição de $\mathrm{VaR}_{95 \%}$ de 1,0 milhão de $\mathrm{R}$ / ano, diferenciando-se as metas.

Pode-se visualisar que a decisão de sazonalização muda consideravelmente nas duas situações em que há restrição de $\mathrm{VaR}_{95 \%}$. Para estas duas situações, existem alocações significativas de energia nos meses de janeiro a março também. Percebe-se que a restrição de $\mathrm{VaR}_{95 \%}$ faz com que a decisão ótima fique mais próxima de uma alocação uniforme ao longo do ano.

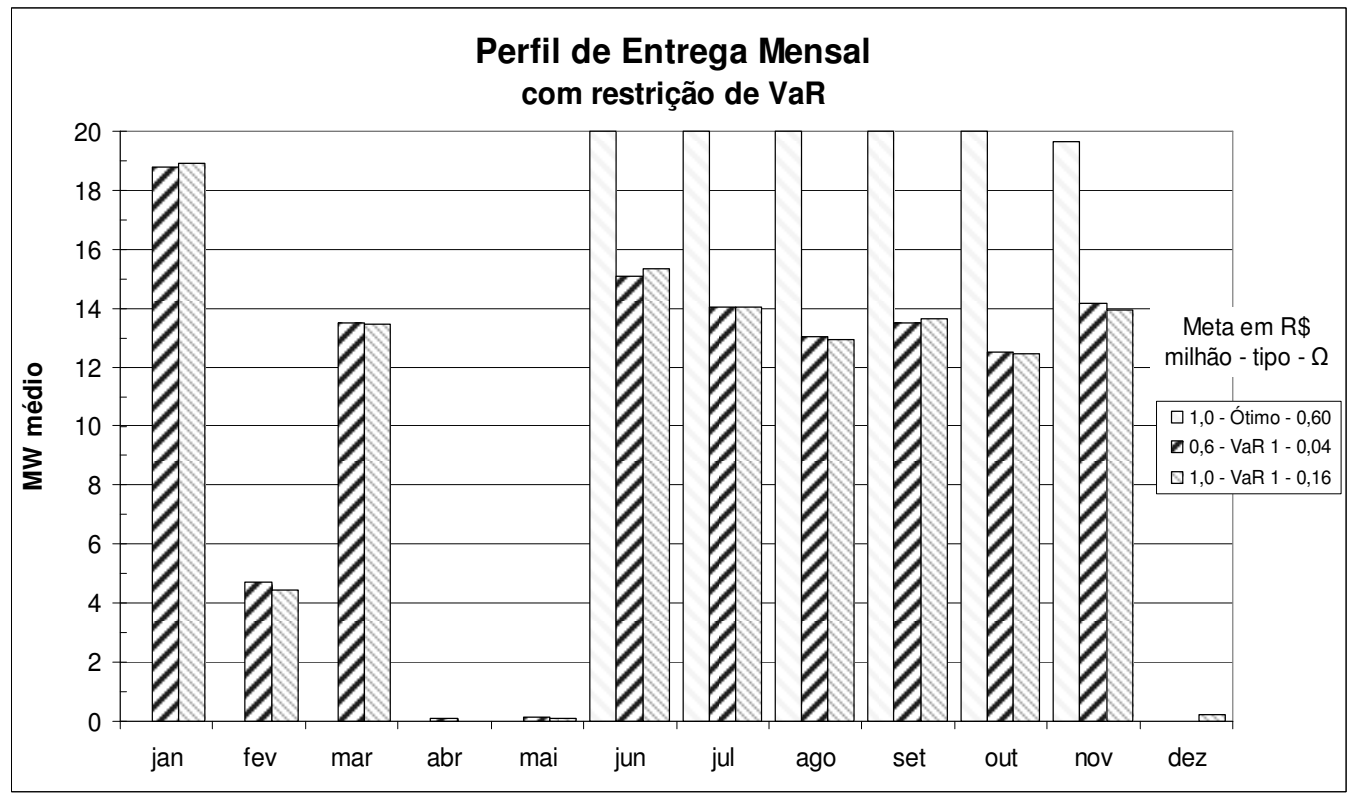

Figura 14 - Perfil Ótimo de Entrega Sazonalizada com Restrição de VaR $\mathbf{R}_{95}$ 


\section{CONCLUSÕES}

Neste artigo, encontrou-se a melhor forma de sazonalizar a energia assegurada de uma usina maximizando o seu resultado tendo-se considerado restrições de $\mathrm{VaR}_{95 \%}$.

No sentido de otimizar o resultado, foi escolhido como critério de seleção da sazonalização a maximização da medida ômega $(\Omega)$, dado um nível de $\mathrm{VaR}_{95 \%}$. A medida $\Omega$ foi escolhida porque consegue incorporar todos os momentos da distribuição, fornecendo uma completa descrição das características do risco-retorno.

Além de procurar responder a uma questão relacionada a um problema real, este trabalho contribui com a utilização de uma técnica recente de otimização de carteira que é a maximização da medida $\Omega$ com restrição de VaR. Adicionalmente, apresenta variáveis e especificidades do SEB pouco exploradas em trabalhos científicos brasileiros.

Os resultados mostraram que os valores da medida ômega diminuem muito rapidamente com o aumento do limite L. Ou seja, se a meta for ousada demais para o tamanho da operação, a relação entre ganho e perda fica muito prejudicada.

Valores mais baixos para o preço do contrato de venda, levando a maiores diferenças possíveis entre os PLDs atingidos (para cima) e o valor base, favorecem ganhos com uma sazonalização ótima da entrega de energia.

A decisão de sazonalização muda substancialmente quando há restrição de VaR. Esta restrição faz com que a decisão ótima fique mais próxima de uma alocação uniforme ao longo do ano. Isto ocorre porque, ao se introduzir uma restrição referente à assunção de risco, a solução encontrada acaba ficando com variações menos bruscas de sazonalização.

Em uma situação extrema, se a restrição de VaR fosse igual a zero, ou seja, sem risco, a solução seria manter a energia assegurada com os mesmos valores ao longo dos meses. Portanto, sem grau de liberdade para realizar a sazonalização.

Como sugestões para trabalhos futuros, a mesma metodologia poderá ser empregada para analisar outras operações no mercado de energia elétrica, tais como: compras descasadas, vendas descasadas e compras sazonais (na safra) de energia produzida a partir do bagaço de cana.

Adicionalmente, a utilização da medida $\Omega$ apresenta grande potencial em estudos de otimização de carteiras de ações e carteiras de projetos com opções reais por considerar todos os momentos das distribuições de probabilidade.

Novos trabalhos podem ser realizados, comparando-se decisões realizadas a partir de medidas clássicas como o índice de Sharpe com aquelas obtidas pelo uso da medida ômega. 


\begin{abstract}
REFERÊNCIAS
CAStro, J. G. Otimização da Performance de um Portfólio de Ativos e Opções Reais utilizando a Medida Omega. Tese de Doutorado, DEI, PUC - Rio, 2008.
\end{abstract}

ICK, M.; NOWAK, E. Omega based Portfolio Optimization - a simulation study on Private Equity investments. Working Paper University of Lugano, Switzerland, 2006.

J.P. Morgan. Risk Metrics. Technical Document, New York, 1996.

JENSEN, M. The Performance of Mutual Funds in the Period 1945-1964. The Journal of Finance, v.23, n.2, May 1968, pp. 389-416.

KAZEMI, H.; SCHNEEWEIS, T.; GUPTA R. Omega as a Performance Measure. Working Paper CISDM. University of Massachusetts, Isenberg School of Management, 2003.

KEATING, C.; SHADWICK, W. A Universal Performance Measure. Journal of Performance Measurement, Spring 2002, pp.59-84.

MACEIRA, M. E. P. ; BEZERRA C. V.. Stochastic stream flow model for hydroelectric systems. In: Proceedings of PMAPS, 1997.

MARKOWITZ, H. Portfolio Selection. The Journal of Finance, v.7, n.1, Mar. 1952, pp. 77-91.

PEREIRA M. V. F.; PINTO L. M. V. G.. Multi-stage stochastic optimization applied to energy planning. Mathematical Programming, 52, 1991.

SHARPE, W. Mutual Fund Performance. Journal of Business, v.39, n.1, 1966, pp.119-138.

TREYNOR, J. How to rate management of investment funds. Harvard Business Review, v.43, n.1, JanuaryFebruary 1965, pp.63-75.

\title{
RESUMO
}

Desde o final dos anos 90, o setor elétrico brasileiro vem passando por grandes reformas, cujos principais objetivos são aumentar a competição e a eficiência na alocação de recursos. Exatamente em função deste aumento de eficiência na alocação de recursos e devido ao consumo sazonal de energia no Brasil, foi estabelecida uma flexibilidade para as hidrelétricas conhecida como sazonalização. A sazonalização permite que a cada ano o agente de geração declare para o próximo ano o quanto é a energia mensal respeitando-se certos limites. Neste artigo, propõe-se um modelo de análise de decisão da sazonalização a partir da otimização da medida ômega com restrições de valor em risco, a qual consegue incorporar todos os momentos de uma distribuição de probabilidade numa análise de decisão. Para o cálculo desta medida, utiliza-se simulação dos preços de curto prazo. Aplica-se este modelo ao caso de uma pequena central hidrelétrica. Os resultados indicam que a decisão de sazonalização muda substancialmente quando há restrição de valor em risco (Value at Risk $\mathrm{VaR}$ ), fazendo com que a decisão ótima fique mais próxima de uma alocação uniforme ao longo do ano. Quando não há restrição de $V a R$, a decisão ótima difere consideravelmente da alocação uniforme.

Palavras-chave: análise de decisão; medida ômega; energia elétrica; simulação; otimização

\section{SEASONNALIZATION DECISION OF CONTRACTS FOR THE SUPPLY OF ELECTRICITY IN BRAZIL THROUGH OPTIMIZATION OF MEASURE OMEGA $\Omega$}

\begin{abstract}
Since the late 1990s, the Brazilian electric power industry has been undergoing significant structural changes, the main objective being to increase competition and resources allocation efficiency. Due to this increase in efficiency and because of seasonal electricity consumption, there is the inclusion of a contractual flexibility, named seazonalization. This flexibility in the contract allows the generation agent (hydropower plant) to choose the monthly electricity amount generated and supplied to the system, each year, within certain limits. In this article it is proposed a model for the analysis and decision of the best energy supply profile, for the twelve months of the contract time span, based on the optimization of the omega measurement (consider all moments), subjected to value at risk restrictions. In order for this omega measurement to be employed, the simulation of short term prices is used and the model then applied to a small hydroelectric generation facility. The results indicate that the seazonalization decision will change substantially when there are value at risk restrictions, forcing the optimal decision to be closer the flat allocation throughout the year.
\end{abstract}

Key words: decision analysis; omega measurement; electricity; simulation; optimization 